Original Article

\title{
Effectiveness of knowledge of result and knowledge of performance in the learning of a skilled motor activity by healthy young adults
}

\author{
Dhara A Sharma, MPT ${ }^{1)}$, Mohamed Faisal Chevidikunnan, $\left.\mathrm{MPT}^{2}\right)^{*}$, \\ Fayaz Rahman Khan, PT, PhD ${ }^{2)}$, RiziQ Allah Gaowgzeh, PT, PhD ${ }^{2}$ ' \\ 1) Ahmedabad Institute of Medical Sciences, India \\ 2) Department of Physical Therapy, Faculty of Applied Medical Sciences, King Abdulaziz University: \\ P.O BOX 90324, Jeddah 21589, Saudi Arabia
}

\begin{abstract}
Purpose] The acquisition of motor skills are fundamental to human life. There is a lack of research on whether knowledge of performance or knowledge of result as augmented feedback is more effective. The objective of this study was to compare the effectiveness of knowledge of result and knowledge of performance in the learning of a skilled motor activity by healthy young adults. [Subjects and Methods] A total of thirty healthy young adult males and females without any neurological or musculoskeletal impairment, between the age of 18-30 years were the subjects of the study. They were randomly allocated to 2 groups: group 1 was given knowledge of result as feedback, and knowledge of performance was given as feedback to group 2. Both the groups practiced the task of throwing a soft spongy ball for 6 days per week for 4 weeks, with 40 trials each day. The outcome measure used was the distance of the throw. [Results] The results were analyzed using the t-test. The mean distances thrown by both the groups showed highly significant improvements and throwing distance of group 2 showed better improvement than that of group 1. [Conclusion] Both types of augmented feedback were effective at improving skilled motor activity, but the knowledge of performance group showed better improvement than the knowledge of result group. Key words: Motor skills, Knowledge of performance, Knowledge of result
\end{abstract}

(This article was submitted Dec. 9, 2015, and was accepted Feb. 1, 2016)

\section{INTRODUCTION}

In human beings, little or no instinctive behavior is inherited. We have a few unlearned reactions (mainly eye blink, knee jerk reflexes, etc.) that serve as signs of normality to the neurologist, but they are not important in understanding human nature. People vary greatly in these inherited capacities, but at the end it is learning that makes the individual distinctive ${ }^{1)}$. Learning can be defined as any relatively permanent change in behavior, or a person's ability to perform a skill, that must be inferred from a relatively permanent improvement in performance which occurs as a result of practice or experience ${ }^{1-3)}$. Learning has also been defined as a process in which various habits, attitudes and knowledge necessary to meet the demands of life in general, are acquired by an individual ${ }^{4}$. While learning is described as the process of acquiring knowledge about the world, motor learning is explained as a set of processes associated with experience or practice which can lead to permanent changes in the ability to perform a skilled action ${ }^{5)}$. Motor learning involves more than motor processes, since it involves learning new strategies for sensing as well as moving. Thus, motor learning emerges from a complex perception, cognition, and action process similar to motor control ${ }^{6)}$.

In order to study motor learning, many variables are considered important determinants. Even though motor skills need to be utilized effectively in a number of situations, and especially in rehabilitation and competitive sports events, there are no

\footnotetext{
*Corresponding author. Mohamed Faisal Chevidikunnan (E-mail: mfaisal@kau.edu.sa)

(C)2016 The Society of Physical Therapy Science. Published by IPEC Inc.

This is an open-access article distributed under the terms of the Creative Commons Attribution Non-Commercial No Derivatives (by-nc-nd) License $<$ http://creativecommons.org/licenses/by-nc-nd/4.0/>.
} 
studies in the literature that have compared different modes of intervention for improving the motor learning of individuals ${ }^{7)}$. The use of feedback, transfer of training, modeling and demonstration, pre-practice instructions, contextual variety and part to whole task practice are among the research areas related to skill acquisitions that are practiced ${ }^{8)}$. Apart from practice itself, feedback to the performer is one of the most critical parts of the learning ${ }^{9}$. Improvement in performance occurs when people have the opportunity to try out movements and are given feedback about the outcome of movements so that they can then rectify or modify their performance to improve the outcome ${ }^{10)}$.

Feedback is a general term that describes information people receive about their performance of a motor skill during or after the performance ${ }^{11)}$. Feedback is very important when it comes to motor learning. Some form of feedback is essential for learning to take place ${ }^{4,12,13)}$. When people perform a motor skill, they have access to two general types of performance related information (i.e. feedback) which will predict the outcome of performance. One is the task intrinsic feedback, the sensory perceptual information that is a natural part of performing a skill. Each of the sensory systems can provide this type of feedback ${ }^{11)}$. The second general type of feedback is augmented feedback. Augmented means adding to, or enhancing something, and in this case it involves adding to or improving task intrinsic feedback. The task intrinsic feedback can be augmented in various ways; however, augmented feedback mainly improves the task intrinsic feedback in two distinct ways. In some situations, augmented feedback improves the task intrinsic feedback, which an individual's sensory system can readily detect on its own. In other situations augmented feedback provides information to an individual when it cannot be detected by the individual's sensory system ${ }^{11)}$. In the process of skill learning, augmented feedback plays two major roles: the first is to facilitate goal achievement of the skill, and the second is to motivate the learner to continue striving towards a goal $^{11,14)}$. There are two types of augmented feedback and they are known as knowledge of performance and knowledge of results ${ }^{15-17)}$. Knowledge of results (KR) can be described as the information related to the performance outcome, whereas knowledge of performance (KP) is related to specific movement component characteristics ${ }^{18,19)}$.

Knowledge of result is knowledge about achieving the goal of the performance or externally presented information about the outcome of performing a skill. In some situations, KR describes something about the performance outcome. Sometimes, KR does not describe the performance outcome, but simply tells the performer whether he or she has achieved the goal of the performance ${ }^{11)}$. KR is beneficial for skill learning for at least four reasons: (a) learners often use KR to confirm their own assessment of the task intrinsic feedback, even though it may be redundant with task intrinsic feedback; (b) learners may need KR because they cannot determine the outcome of performing a skill on the basis of the available task intrinsic feedback; (c) learners often use KR to motivate themselves to continue practicing; and (d) in certain situations, in order to establish a discovery learning practice environment, the practitioner may want to provide only KR. In these situations, as the primary means of learning is to perform a skill, learners are encouraged to engage in a trial and error method of skill performance ${ }^{11)}$.

Knowledge of performance is the second category of augmented feedback. It is information about the movement characteristics that lead to the performance outcome. KP can be given verbally and there are various non-verbal means of providing KP: for example, a videotape replay is a popular method of showing a person what he or she did while performing a skill ${ }^{11,17)}$. KP can be especially beneficial when: (a) skills must be performed according to specified movement characteristics, such as in gymnastics, stunts, or springboard dives; (b) a specific movement component of skills that requires complex coordination must be improved or corrected; (c) the goal of the action is a kinematic, kinetic, or specific muscle activity; or (d) KR is redundant in the task intrinsic feedback ${ }^{11)}$.

Feedback can improve the motor learning of healthy subjects. Careful planning of scheduling, content and attention oriented focus induced by feedback can improve the effectiveness of training considerably ${ }^{17}$. Even though motor tasks can be learned without extrinsic feedback, comparisons of KP and KR with no feedback show there is improved retention with feedback ${ }^{17,20,21)}$. Since the available evidences do not provide clear-cut evidence about the relative effectiveness of KR and $\mathrm{KP}^{20}$, studies are needed to determine which is more effective at improving motor learning. Accordingly, the objectives of this study were to understand and compare the effectiveness of KR and KP for healthy young adults learning a skilled motor activity with the non-dominant upper limb.

\section{SUBJECTS AND METHODS}

This quasi experimental study recruited thirty healthy young adult male and female subjects, aged between 18 to 25 years, who were attending a physical therapy school. The study was approved by the Institutional Ethical Review Committee of King Abdulaziz University. The subjects were explained about the experimental procedures, outcome measures, and formal written informed consent was obtained from each participant. The exclusion criteria were: deformity either congenital or acquired, pain in the non-dominant upper extremity, trauma of the upper extremity, severe cardiovascular deficit, or neurological deficit. The 30 subjects were randomly allocated to group 1 or group 2 by a lottery method. The task which was given to both the groups was to throw a soft spongy ball as far as possible with the non-dominant arm. The pre-test measure was the mean distance the subjects of each group could throw the soft spongy ball in five trials, without practice.

In group $1(\mathrm{KR})$, all the subjects practiced throwing the soft spongy ball 40 times a day. Each subject rested for 40 seconds after every 10 trials. After every 10 trials the subjects were given knowledge of result as feedback, in the form of the longest distance thrown by them in the 10 trials. The practice sessions were performed for four weeks with six sessions per week.

In group $2(\mathrm{KP})$, the subjects were given the same practice task as group 1; however, after 10 trials they were given 
Table 1. Comparison of the pre and post- test throwing distances (feet) of group 1 which received KR and of group 2 which received KP

\begin{tabular}{lccccc}
\hline Group & \multicolumn{2}{c}{ Pre-test } & \multicolumn{2}{c}{ Post-test } & Improvement \\
& Mean & $\begin{array}{c}\text { Standard } \\
\text { deviation }\end{array}$ & Mean & $\begin{array}{c}\text { Standard } \\
\text { deviation }\end{array}$ & \begin{tabular}{c} 
mean \\
\hline Group 1 (KR)
\end{tabular} \\
\hline Group 2 (KP) & 35.30 & 9.22 & 58.46 & 9.50 & $23.16^{*}$ \\
\hline$* \mathrm{p}<0.05$ & 35.77 & 8.61 & 64.72 & 9.49 & $28.94^{*}$ \\
\hline
\end{tabular}

Table 2. Intergroup comparison of the pre and post- test throwing distances (feet) of the KR and KP groups

\begin{tabular}{lcccc}
\hline & Pre-test & Post-test & $\begin{array}{c}\text { Mean of } \\
\text { improvement }\end{array}$ & $\begin{array}{c}\text { Difference in } \\
\text { improvement }\end{array}$ \\
\hline Group 1 (KR) & 35.30 & 58.46 & 23.16 & $5.78^{*}$ \\
Group 2 (KP) & 35.77 & 64.72 & 28.94 & \\
\hline$* \mathrm{p}<0.05$ & & & &
\end{tabular}

feedback in the form of knowledge of performance, i.e. verbal cues and videotape replays of their own performance. The practice sessions were performed for four weeks with six sessions per week. The post-test throwing distance was measured at the end of the four weeks as the average of 5 trials performed by the subjects of both the groups.

The data were statistically analyzed using the statistical package, SPSS for Windows version 19.0. Statistical significance was accepted for values of $\mathrm{p}<0.05$. The data of the throwing distance of both the groups were analyzed using the paired $t$-test. The mean, standard deviation and the standard error were calculated for the throwing distance of both the groups, and the inter-group comparison was done using the unpaired t-test.

\section{RESULTS}

In group 1, the pre-test mean of throwing distance was $35.30 \pm 9.22$ feet, and the post-test mean was $58.46 \pm 9.50$ feet which shows there was an improvement in the mean throwing distance of group 1 . The pre and post-test comparison of group 1 showed there was an improvement of 23.16 feet $(\mathrm{p}<0.05)$ (Table 1$)$.

In group 2, the pre-test mean of throwing distance was $35.77 \pm 8.61 \mathrm{feet}$, and the post-test mean was $64.72 \pm 9.49$ feet which shows there was an improvement in the mean throwing distance of group 2 . The pre and post-test comparison of group 2 showed there was an improvement of 28.94 feet $(\mathrm{p}<0.05)$ (Table 1$)$.

The inter-group comparison was done using the unpaired t-test, and the difference in the mean improvements of the groups was 5.78 feet $(\mathrm{p}<0.05)$, a significant result in the group $2(\mathrm{KP})$ showed greater improvement (Table 2 ).

\section{DISCUSSION}

The purpose of this study was to investigate the effectiveness of augmented feedback in the form of knowledge of result and knowledge of performance in the learning of a skilled motor activity by healthy young adults. The ball throwing distance of the non-dominant arm was used as the outcome measure, and practice sessions were conducted 6 days a week for 4 weeks. Group 1 received knowledge of result as feedback whereas group 2 received knowledge of performance as feedback.

In order to enhance motor learning, feedback can be used in any form, especially in the form of augmented feedback ${ }^{17,22)}$. The result of this study shows that, KR as feedback for improving the motor learning is effective for young adults. This finding is supported by Carolee Winstein et al. ${ }^{10)}$ who stated that knowledge of results is capable of affecting both temporary and relatively permanent (i.e. learning) changes in performance, especially in motor learning. Sidaway B et al. ${ }^{23)}$ reported that even though all their study groups improved with practice, the immediate KR group performed better than the other groups. John Liu \& Craig A. Wrisberg ${ }^{24)}$ also concluded that KR is an effective method of feedback for improving the motor skills of the subjects. Masters et al. ${ }^{25}$ ) reported that objective and marginally perceptible knowledge of results was an effective mode of feedback for the subjects they tested for improved performance. Even though KR has been developed in the field of experimental psychology, this motor learning theory is now practiced in various fields of physical therapy. However the within-group comparison of the KP group also showed there was a significant improvement at the end of the program. This finding could be in agreement with the study results of Zubiaur $\mathrm{M}$ et al. ${ }^{26)}$, who stated that knowledge of performance tends to be an effective mode of intervention for learning.

The intergroup comparison showed there was a very highly significant difference in the distance thrown between the 
KR and the KP groups. The reason for this significant improvement in KP could be that the knowledge of performance of repetitive movements results in better motor outcomes. According to Cirstea $\mathrm{C} \mathrm{M}$ et al. ${ }^{27)}$, if an appropriate feedback is given (ie, KP), even severely impaired patients may show improvement in motor function. Other reasons for better performance in the KP group were suggested by Leonard F. Koziol and Deborah Ely Buddin ${ }^{28}$ ) who concluded that while factual information is consciously recalled in explicit or declarative memory, in procedural learning, memories and acquisitions are demonstrated through task performance. The fact that acquisition can occur very quickly in declarative learning, even with a single exposure to an event, but usually requires repetition of an activity in procedural learning and associated learning, is demonstrated through improved task performance. Hence, when the knowledge of performance was given as a feedback, it served the right purpose. Tzetzis et al. ${ }^{29}$ ) showed that, for learning a physical skill, goal setting and feedback are among the most important factors. However, they suggested that, feedback does not improve performance when feedback is separated from goals. Intuitively, this makes sense as in any kind of coaching instruction there is typically some sort of goal involved, because the nature of feedback has to refer to a goal even if it is implicit. Even the use of observation can lead to improvement in the cognitive representations of the movement through recall and recognition. Therefore, adding a feedback can enhance the effectiveness of performance in all individuals ${ }^{7,18)}$.

The results of the study also suggest the effective use of these feedbacks for enhancing motor learning and thereby performance, especially that of athletes. Feedback could be effectively used in various disciplines to improve recovery and performance following injury and in particular during the rehabilitation period. The common factor in both KP and KR is that both sources of information are provided externally ${ }^{16}$. Augmented feedback was found to be useful for improving the performance of athletes as well as the process of motor learning ${ }^{30}$. It could also be used in sports injury prevention, rehabilitation and training ${ }^{16)}$. According to Gabriele Wulf et al. ${ }^{5,31)}$, feedback can affect learners' performance, motivation, and learning. This may have an energizing or reinforcing effect that facilitates motor learning. For successfully performing physical activities in daily life, motor skill learning is an essential component. In neuroscience, understanding the mechanisms of motor learning in the human nervous system remains an interesting scientific issue. It is important to increase the effectiveness of motor skill learning in the fields of sports science and neurological rehabilitation. Accordingly, we expect these findings will help the development of effective and efficient approaches for the facilitation of motor learning ${ }^{8}$.

In the present study, only a simple ball- throwing task was analyzed and that is one of the limitations of this study. It could be the reason for low improvement difference between the groups, and a more complex task might have provided a more definitive result. Moreover, the retention of the learned movement was not investigated. A larger scale study with follow up is recommended which may clarify the problem in a better way. Future studies should focus on conducting studies using patient populations with multiple outcome measures and more complex tasks to better elucidate improvements in performance. In conclusion, the result of this study shows that both the groups showed improvements in the ball-throwing distance of the non dominant upper extremity of healthy young adults, and the group which received KP as a feedback showed greater improvement in the skilled motor activity.

\section{REFERENCES}

1) Morgan CT: A brief introduction to psychology, 2nd ed. Chapter 4, The principles of learning. 1996, pp 78-79.

2) Fischman MG: Motor learning and control foundations of kinesiology: defining the academic core. Quest, 2007, 59: 67-76. [CrossRef]

3) Kwon YH, Yeo SS, Kwon JW, et al.: Neuromuscular adaptation induced by motor imagery training in the serial reaction time task. J Phys Ther Sci, 2010, 22: 413-418. [CrossRef]

4) Nataraj P: Psychology. Part 1, Chapter 7, Learning, 1st ed. 1996, p 172

5) Yoon JG, Yook DW, Suh SH, et al.: Effects of self-controlled feedback on balance during blocked training for patients with cerebrovascular accident. J Phys Ther Sci, 2013, 25: 27-31. [CrossRef]

6) Cook AS, Woollacott MH: Motor control theory and practical applications. Chapter 2, Motor learning and recovery of function, 2nd ed. Lippincott Williams and Wilkins, 2001, pp 26-43.

7) Ste-Marie DM, Law B, Rymal AM, et al.: Observation interventions for motor skill learning and performance: an applied model for the use of observation. Int Rev Sport Exerc Psycho, 2012, 5: 145-176. [CrossRef]

8) Kwon YH, Kwon JW, Lee MH: Effectiveness of motor sequential learning according to practice schedules in healthy adults; distributed practice versus massed practice. J Phys Ther Sci, 2015, 27: 769-772. [Medline] [CrossRef]

9) Winstein CJ: Knowledge of results and motor learning_implications for physical therapy. Phys Ther, 1991, 71: 140-149. [Medline]

10) Winstein C, Wing AM, Whitall J: Handbook of Neuropsychology; Motor control and learning principles for rehabilitation of upper limb movements after brain injury, 2nd ed. Elsevier Science B.V, 2003, pp 77-138.

11) McGill RA: Motor learning concepts and applications, 6th ed. Mc Grawhill, 2001, pp 169, 235-244, 246-263.

12) Yeldan I, Huseyınsınoglu BE, Akıncı B, et al.: The effects of very early mirror therapy on functional improvement of the upper extremity in acute stroke patients. J Phys Ther Sci, 2015, 27: 3519-3524. [Medline] [CrossRef]

13) Yamamoto R, Ohashi Y: The effects of inaccessible visual feedback used concurrently or terminally. J Phys Ther Sci, 2014, 26: 731-735. [Medline] [CrossRef]

14) van Dijk H, Jannink MJ, Hermens HJ: Effect of augmented feedback on motor function of the affected upper extremity in rehabilitation patients: a systematic review of randomized controlled trials. J Rehabil Med, 2005, 37: 202-211. [Medline] [CrossRef]

15) Weeks DL, Kordus RN: Relative frequency of knowledge of performance and motor skill learning. Res Q Exerc Sport, 1998, 69: 224-230. [Medline] [Cross- 
Ref]

16) Lauber B, Keller M: Improving motor performance: selected aspects of augmented feedback in exercise and health. Eur J Sport Sci, 2014, 14: 36-43. [Medline] [CrossRef]

17) Vliet PM, Wulf G: Extrinsic feedback for motor learning after stroke: what is the evidence? Disab Rehab, 2006, 28: 13-14, 831-840.

18) Magill RA: 1997 C. H. McCloy Research Lecture: knowledge is more than we can talk about: implicit learning in motor skill acquisition. Res Q Exerc Sport, 1998, 69: 104-110. [Medline] [CrossRef]

19) Keogh JW, Hume PA: Evidence for biomechanics and motor learning research improving golf performance. Sports Biomech, 2012, 11: 288-309. [Medline] [CrossRef]

20) Herbert E, Landin D, Menickelli J: Videotape feedback: what learners see and how they use it. J Sport Pedagog, 1998, 4: 12-28.

21) Thorpe DE, Valvano J: The effects of knowledge of performance and cognitive strategies on motor skill learning in children with cerebral palsy. Pediatr Phys Ther, 2002, 14: 2-15. [Medline] [CrossRef]

22) Sigrist R, Rauter G, Riener R, et al.: Terminal feedback outperforms concurrent visual, auditory, and haptic feedback in learning a complex rowing-type task. J Mot Behav, 2013, 45: 455-472. [Medline] [CrossRef]

23) Sidaway B, Moore B, Schoenfelder-Zohdi B: Summary and frequency of KR presentation effects on retention of a motor skill. Res Q Exerc Sport, 1991, 62: 27-32. [Medline] [CrossRef]

24) Liu J, Wrisberg CA: The effect of knowledge of results delay and the subjective estimation of movement form on the acquisition and retention of a motor skill. Res Q Exerc Sport, 1997, 68: 145-151. [Medline] [CrossRef]

25) Masters RS, Maxwell JP, Eves FF: Marginally perceptible outcome feedback, motor learning and implicit processes. Conscious Cogn, 2009 , 18: 639-645. [Medline] [CrossRef]

26) Zubiaur M, Oña A, Delgado J: Learning volleyball serves: a preliminary study of the effects of knowledge of performance and of results. Percept Mot Skills, 1999, 89: 223-232. [Medline] [CrossRef]

27) Cirstea CM, Ptito A, Levin MF: Feedback and cognition in arm motor skill reacquisition after stroke. Stroke, 2006, 37: 1237-1242. [Medline] [CrossRef]

28) Koziol LF, Budding DE: Encyclopedia of the Sciences of Learning. Procedural Learning; Springer, 2012, pp 2694-2696.

29) Tzetzis G, Kioumourtzoglou E, Mavromatis G: Goal setting and feedback for the development of instructional strategies. Percept Mot Skills, 1997, 84: 1411-1427. [Medline] [CrossRef]

30) Post PG, Fairbrother JT, Barros JA: Self-controlled amount of practice benefits learning of a motor skill. Res Q Exerc Sport, 2011, 82: 474-481. [Medline] [CrossRef]

31) Wulf G, Chiviacowsky S, Lewthwaite R: Normative feedback effects on learning a timing task. Res Q Exerc Sport, 2010, 81: 425-431. [Medline] [CrossRef] 